\title{
The Contribution of Professor Yujiro Ikemi to the Development of Psychosomatic Medicine in Japan
}

\author{
Chiharu Kubo \\ Department of Psychosomatic Medicine, Graduate School of Medical Sciences, Kyushu University, \\ Fukuoka, Japan
}

Dr. Yujiro Ikemi, Professor Emeritus of Kyushu University, died on June 25, 1999, at age 84 . With great sorrow, I write about my teacher, the late Dr. Ikemi, one of the world's leading psychosomatists who developed new concepts, made new discoveries and gave new meaning to the expanding field of psychosomatic medicine. His contribution towards integrating Oriental wisdom into Western psychosomatic medicine and bringing forth the ancient wisdom of Asia is recognized throughout the scientific communities of the World.

Dr. Ikemi was born on June 12, 1915, in Fukuoka, Japan. After graduating from Fukuoka High School, he entered the faculty of medicine of Kyushu University. During that phase of his life, he began to suffer from irritable bowel syndrome in addition to social phobia, and received various treatments without satisfactory response.

Fortunately, in 1951, he went to the US as a fellow of the Institute of Tuberculosis of the Mayo Clinic in Minnesota. In the US he had a chance to study psychosomatic medicine, not only at the Mayo Clinic, but also at psychosomatic centers in America, including the Menninger Foundation.

After returning to Japan, he was appointed to the position of Associate Professor of the Department of Internal Medicine at Kyushu University. He then decided to con- centrate his efforts toward pioneering work in the field of psychosomatic medicine in Japan. His first important work, a special lecture on 'Psychosomatic Aspects of the Gastrointestinal System', came to light at the Annual Congress of the Japanese Society of Gastroenterology in 1955. He and his co-workers collected experimental evidence of functional changes in the gastrointestinal system induced by strong emotional reactions to hypnotic suggestion. Eventually, his work convinced skeptical researchers in Japan, promoting increased interest in psychosomatic medicine among physicians throughout Japan.

In 1958, at the World Congress of Gastroenterology in Washington, he presented the paper 'Experimental Studies on the Psychosomatic Disorders of the Digestive System'. This paper created tremendous interest among gastroenterologists in the US including one of the leading gastroenterologists, Professor Bockus, who invited him to contribute his work to his textbook on gastroenterology.

In 1958, Professor E. Weiss, one of the pioneers of psychosomatic medicine, invited him to the Department of Comprehensive Medicine of Temple University Medical Center as an instructor. Fortunately, this association gave him a supporting hand when he built up the Department of Psychosomatic Medicine at Kyushu University School of Medicine.

\begin{tabular}{ll}
\hline KARGER & ( ) 2000 S. Karger AG, Basel \\
Fax +4161306 1234 $34-3190 / 00 / 0692-0057 \$ 17.50 / 0$ \\
$\begin{array}{l}\text { E-Mail karger@karger.ch } \\
\text { www.karger.com }\end{array}$ & $\begin{array}{l}\text { Accessible online at: } \\
\text { www.karger.com/journals/pps }\end{array}$
\end{tabular}

Chiharu Kubo, MD

Department of Psychosomatic Medicine

Graduate School of Medical Sciences, Kyushu University

3-1-1 Maidashi, Higashi-ku, Fukuoka 812-8582 (Japan)

Tel. +81 92642 5318, Fax +81 92642 5336, E-Mail ckubo@cephal.med.kyushu-u.ac.jp 
Upon returning to Japan in 1959, he visited Professor $\mathrm{T}$. Miura, one of the most distinguished Japanese psychiatrists at that time, who was also interested in psychosomatic medicine. With the support and help of Professor Miura, Associate Professor Ikemi founded the Japanese Society of Psychosomatic Medicine and organized the First Congress of this Society, held in Tokyo in 1960, under the presidency of Professor Miura. In 1961, with the support of the Japanese Minister of Education, Dr. Ikemi established the first Institute of Psychosomatic Medicine in Japan at Kyushu University and was appointed as the professor of the Institute. In 1963, this institute developed a new department of psychosomatic medicine, following the system of the Department of Comprehensive Medicine of Temple University Medical Center.

In 1967, he organized the Second International Congress of Psychosomatic Medicine and Hypnosis in Kyoto. At the same time, he also became Chairman of the Committee of Psychosomatic Medicine of the World Psychiatric Association and served in this position distinguishably for 15 years.

In 1977, the Fourth Congress of ICPM was held in Kyoto under his presidency. His lecture on 'The Integration of Occidental and Oriental Psychosomatic Treatment' was not only a masterpiece, but also the focus of the congress. It energized the Western participants about the importance of Oriental approaches for the further development of psychosomatic medicine. Under his leadership, this congress, in a real sense, opened the dialogue in psychosomatic medicine between the East and West.

The Karger Publishing Company published a special issue of the Karger Gazette 'The Wisdom of the Body', which was written by an editor of the Gazette based on Dr. Ikemi's presidential address with the intention of stimulating an increased interest towards the importance of Oriental wisdom in Western physicians.

Dr. Ikemi served the Japanese Psychosomatic Society as president until 1991, and at the time of his death was Emeritus President. He was also the first Asian to become
President of the ICPM. He had written prolifically and brought ancient wisdom, in his own way, to the whole world, so that holistic medicine could become the focus of therapy for human beings worldwide. He contributed towards the concept of somatization and laid the biopsychosocioecological foundation for psychosomatic medicine. His enthusiasm toward the education of Asian countries led him to form the Asian College of Psychosomatic Medicine, and he was responsible for establishing the Visiting Professorship in Psychosomatic Medicine sponsored by the World Health Organization and the Asian Chapter of the International College of Psychosomatic Medicine. His pioneering research on spontaneous remission in terminal cancer patients demonstrated that a strong faith and belief system was the common thread in the fabric of human life. In recent years, he had devoted his time and talent toward integrating Oriental somatopsychic and self-regulation methodologies into Western medicine, including Yoga, Qigong, Zen meditation, Japanese dance and acupuncture. For his scientific contribution to the world, he received the Hans Selye Award in Geneva in 1992 and was honored as a great theoretician, philosopher, scientist and, above all, as a teacher. His contributions continued to flow throughout the world and, until the time of his death, he was defining a new concept of self-holistic approaches to medicine for the benefit of mankind. His work in research and teaching has facilitated an existential shift in human beings to make their lives rewarding and successful. He wrote numerous books that have been published in various languages, including English and French. His wisdom, knowledge, research activities and teachings were so vast that numerous members of the scientific community had requested Dr. Ikemi to bring out a book on the integration of Occidental and Oriental psychosomatic medicine. Even though suffering for years from a fatal disease, he continued to work as a researcher, clinician and teacher with tremendous effort until the last moment of his life.

We all sincerely pray for the repose of Dr. Ikemi's soul. 